\title{
Corpus-based Instruction and the Acquisition of Functional Lexical Bundles: EFL Egyptian School Learners' Perspective ${ }^{(*)}$
}

\author{
Supervised by \\ Professor Amira Agameya
}

\author{
Dina M. Nour \\ Faculty of Arts \\ Cairo University
}

\begin{abstract}
The main purpose of this case study is to reflect on EFL school learners' attitudes towards the efficacy of corpus-based instruction in the acquisition of functional lexical bundles. Seven Egyptian EFL school learners participated in this study and expressed their views about the new teaching and learning experience of lexical bundles after finishing a ten-week English course. During this period, the 7 students studied selected and filtered printed out concordances, under the guidance of their teacher, to acquire fifteen functional lexical bundles. The researcher held one whole group interview with the participants after they had finished the course. The data taken from the interview was qualitatively analyzed to denote three main themes about the effectiveness of corpus instruction in the acquisition of lexical bundles, in addition to the problems they had encountered during the course, and the recommendations they offered for enhancing the new learning experience. Results showed that all learners had positive attitudes towards the efficiency of corpus-based instruction as a successful means of teaching and learning the targeted lexical bundles
\end{abstract}

\section{Keywords}

formulaic language, lexical bundles, corpus-based instruction, concordance,

(*)Corpus-based Instruction and the Acquisition of Functional Lexical Bundles: EFL Egyptian School Learners' Perspective, Vol.10, Issue No.3, July 2021, pp.89-116. 
explicit instruction, data-driven learning.

\section{الملخص}

تهدف دراسة الحالة إلى عرض انطباعات طلاب المدارس من مستخدمي اللغة

الإنجليزية كلغة ثانية عن مدى فاعلية التعليم باستخدام المخزون اللغوي في اكتساب حزم لفظية

ذات نمط وظيفي. شارك في الدراسة سبعة من طلاب المدارس المصريين الذين عبروا عن

آرائهم تجاه التجربة التعليمية الجديدة، وذلك بعد إنهائهم دورة لتعليم اللغة الإنجليزية استمرت

لعشرة أسابيع. قام الطلاب خلال تلك الفترة بدراسة بعض الفهارس المطبوعة من المخزون اللغوي بعد تتقيحها بهد اكتساب خمس عشرة حزمة لفظية من النمط الوظيفي وذلك تحت إثراف المدرس المسؤول. بعد انتهاء الدورة التعليمية، قام الباحث بتسجيل مقابلة جماعية مع الطلاب المشتركين بالدراسة. فُرغت هذه التسجيلات بواسطة الباحث الذي أجرى عليها تحليلا نوعيًّا، وذلك للوصول إلى ثلاث نتائج رئيسة خاصة بفاعلية التعليم بواسطة المخزون اللغوي وما قد يحتويه من معوقات، إلى جانب التوصيات من أجل الوصول إلى تجربة تعليمية أفضل. جاءت النتائج موضحة لآراء الطلاب الإيجابية تجاه التعليم القائم على المخزون اللغوي وذلك لنجاحه في مساعدة الطلاب في اكتساب الحزم اللغوية المستهدفة من الدراسة.

الكلمات المفتاحية

اللغة المعدلة، الحزم اللفظية، التعليم القائم على المخزون اللغوي، الفهرس، التعليم الصريح،

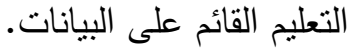

Recently, "dictionary consultation, corpus consultation, and data driven learning (DDL) activities" have been found effective in clarifying language formulacity, not to mention that they have double benefits as they could be applied in classes guided by teachers or in other environments, where learners could perform their assigned activities (Meunier, 2012). However, evaluating the effectiveness of DDL, which 


\section{Dina M. Nour}

mainly relies on printed-out concordance in the area of vocabulary acquisition was not fully investigated by research in spite of the fact that the field of corpus has been found very productive in teaching sophisticated patterns of language as lexical bundles (Meunier, 2012).

The purpose of the present study is to elaborate on the views of Egyptian EFL school learners on corpus-based instruction as one type of DDL in the acquisition of 15 functional four-word lexical bundles.

1. What is the Egyptian EFL school learners' perspective of the efficacy of corpus-based instruction in the acquisition of functional lexical bundles?

\section{Theories on Language Acquisition}

In the field of second language acquisition (SLA), there are a variety of theories stressing the necessity of intentional and attentive learning as vital tools to attain the acquisition of second or foreign languages. For example, there is Schmidt's noticing hypothesis, which states that noticing the linguistic input is a crucial factor to internalize the targeted language into learners systems, only after attentively learning it and being aware of form-meaning relations (Schmidt, 1990).

Another important approach that is related to noticing linguistic and grammatical features in input is Long's (1997) approach Focus-onform (FonF), which is about drawing learners' attention to contextualized language items (such as "words, collocations, grammatical structures, pragmatic patterns") that emerge incidentally in linguistic texts, where content and communicative skills are assumed to be the main focus; in addition, it also consolidates the idea of acquiring forms by storing them in memory even without recognizing what they mean or how they function at the beginning. In a nutshell, FonF works by making learners in control of their learning, thereby enabling them to have total or partial comprehension of new linguistic items (Long, 1997).

The process of studying words as phrases (this area of studying is referred to in the linguistic field as phraseology) has drawn attention to 
the importance of acquiring form, meaning and usage of words in chunks similar to the way that was applied by first language users, and consequently it has been found essential for the acquisition of both foreign language (FL) and second language (SL) (Huang, 2015).

\section{Lexical Bundles}

Paquot and Granger (2012) defined lexical bundles as "the repetition of contiguous strings of words of a given length" (p.138). In terms of their semantics, lexical bundles are distinguished from other idiomatic phrases by their clarity in meaning compared to single words since their focus is on how formulaic and not how idiomatic a language is (Ruan, 2017).

Traditionally, a top-down perspective was employed to approach word combinations through examining their linguistic role; while more recently the investigation of word combinations has depended on corpus analysis, or bottom-up approaches, which examines how formulaic expressions are distributed and frequently used in the language, instead of focusing only on their linguistic role (Lenko-Szymanska, 2014).

It has also been formerly noticed that if the length of the bundle is extended to more than four words, it is less frequently adopted by learners (Huang, 2015). To elaborate, a bundle constituting four words is marked with more frequency compared to a bundle of five words, and it is also more fulfilling in function and structure than a bundle of three words (Kashiha \& Chan, 2015). For the previously mentioned reasons, four-word bundles were considered the best option to be selected for the present study.

Lexical bundles have a major functional role in building a language (Amirian, Ketabi, \& Eshaghi, 2013). Functional lexical bundles, which are most frequently used in academic writing regarding their structure and meaning, are categorized into three groups according to Hyland (2008), which are research lexical bundles, whose use frame writers' 


\section{Dina M. Nour}

observations of actual incidents, text-oriented bundles, which are responsible for organizing texts to deliver meaningful ideas, and participant-oriented bundles, whose function is to represent the stance of writers or readers. Fifteen functional four-word lexical bundles were selected from the previous three types to be investigated in the present study.

\section{Explicit Instruction of Lexical bundles}

It has been pointed out that learners should notice the targeted multi-word units for an intentional learning process to occur (LeńkoSzymańska, 2014). Since explicit instruction directly instructs learners on the meaning of words, therefore, it is recommended due to the fact that it makes it easier for them to notice word forms and how meanings are mapped (Kweon \& Kim, 2008).

After being exposed to texts on regular basis learners gain knowledge of some words; later, when they start their oral or written production, their language selection relies on the words they have repetitively encountered in previous texts that have similarity to the recent ones they are using, and then acquisition takes place (Hyland \& Tse, 2009). Therefore, it has been found effective to repetitively expose learners to the targeted words for full acquisition of meaning, form and function to take place.

\section{The corpora's use in teaching and learning}

The corpus is a computerized system for the collection and storage of natural contextualized scripts of spoken and written discourse, which functions explicitly to meet many requirements of language users (Kayaoglu, 2013). Through the corpus, learners can enhance their vocabulary knowledge including the attainment of fluency and accuracy by being exposed to a variety of lexis; and teachers can identify learners' problems by going through original texts produced by $\mathrm{Fl}$ and L2 learners (Kayaoglu, 2013). Not only that, but there are also more gains of exploiting the corpus in foreign and second language teaching and 
learning, which is clear in the way it boosts learners' knowledge of languages and cultures while improving their communicative skills due to the highlighted meanings and forms of a contextual language (Hanafiyeh \& Keshi, 2013).

By means of corpus analysis, the prevalence of formulaic sequences and their impact on attaining fluency in spoken and written language have been detected (Allan, 2016). Recently, there has been a continuous reliance on corpus to detect word-patterns by investigating big amounts of spoken and written discourse (Adel \& Erman, 2012). The reason of this kind of attention to corpora has been due to the complication of formulaic language acquisition encountered by learners and academic writers, who are not proficient enough; add to this the fact that the measurement and identification of formulaic sequences in natural settings have been proved problematic (Adel \& Erman, 2012).

\section{Corpus-Based Instruction of Lexical Bundles}

Corpus-based instruction has also drawn attention as an inductive method, which motivates autonomous learning since students independently go through various stages to induce the language they aim to acquire. The corpus has encouraged the emergence of some learning styles such as autonomy, which is related to learners' elicitations of linguistic forms, meanings, and functions after being constantly relying on the concordance lines of the corpora (Hanafiyeh \& Keshi, 2013). Regarding the acquisition of formulaic language, going through the concordances has a positive impact on the way a language is taught and learnt since the corpus is exploited by learners to identify authenticity in a language and recognize its patterns (Jafarpour, Hashemian, \& Alipour, 2013).

One method of learning that is based on corpus in class is called data-driven learning, which triggers students' ability of exploring the target language (TL) patterns, and results in developing tasks relying on the output of concordance (Guan, 2013). DDL is basically applied when 
using the corpora as a tool of learning foreign or second language in a clear and direct way, which can either be done via electronic means, or by using paper-based work (Krummes \& Ensslin, 2015).

\section{Research Design}

This is a case study, which employed a qualitative instrument (a whole group interview) in collecting data. For a period of ten weeks, fifteen four-word lexical bundles were taught by applying corpus-based instruction, where printed out concordances of fifteen functional lexical bundles were used by the students. To answer the research question, a qualitative analysis was drawn on the data collected from one semistructured whole group interview.

\section{Participants}

Seven students participated in this study, three boys and four girls. They have the same learning environment by going to the same school and sharing the same educational background since they all study for the International Baccalaureate (IB). They also share the same proficiency level, which was the intermediate level. However, they are of different ages (see Table 1). Since the participants were under the age of 18, their parents signed consent forms permitting the participation of their children in the study.

Table 1

Demographic Data of the Participants

\begin{tabular}{|c|c|c|}
\hline participants & Gender & Age \\
\hline$\overline{\mathrm{A} 1}$ & Female & 13 \\
\hline $\mathrm{A} 2$ & Female & 12 \\
\hline A3 & Male & 12 \\
\hline A4 & Female & 13 \\
\hline A5 & Female & 13 \\
\hline A6 & Male & 12 \\
\hline A7 & Male & 15 \\
\hline
\end{tabular}


Note. The symbols A1-A7 are used to represent each member of the participants

\section{The Teacher}

The teacher, who applied corpus based instruction on the participants, is an Egyptian female with a teaching experience of twelve years. She received her Master's degree in Teaching English as a Foreign Language (TEFL) from the American University in Cairo (AUC). One of her Master's courses was corpus-based linguistics, so she has good knowledge of concordances and corpus analysis; however, it was her first experience with corpus-based instruction. She has taught in different universities; as for her experience with teaching school students, it was her second experience with the participants of the present study. It is worth mentioning that she has taught students of different ages and different proficiency levels.

\section{Setting}

The study was conducted as part of a learning program called Young Learners English (YLE). YLE is a course offered by the School of Continuing Education (SCE) at the American University in Cairo (AUC). The students' proficiency levels are decided after taking a placement test before they join the courses. There are 10 sessions in a YLE course, which lasts for ten weeks, with a duration of two hours per session. At the time of the study, the last 30 minutes of each session was devoted to teaching the targeted lexical bundles by applying corpus-based instruction. Every Saturday morning the participants attended a two-hour session for a period of ten weeks. The whole course started on November $23^{\text {rd }} 2018$ and ended on January $26^{\text {th }} 2019$.

\section{Selection of the Targeted Lexical Bundles}

With regard to Hyland (2008) categorization of lexical bundles, three types of lexical bundles were selected for instruction: research, textoriented and participant-oriented lexical bundles. The selection of lexical bundles also relied on the Academic Word List (AWL) presented in 
Hyland and Tse (2009). This is due to the fact that a variety of categories and subcategories of the most frequently used lexical bundles in written and spoken discourse is presented in the AWL.

Regarding the lexical bundles selected from each type and their number, seven text-oriented lexical bundles were selected, due to their importance in transition of ideas in writing, which are as a result of, it is important to, due to the fact, in addition to the, on the other hand, on the basis of and in contrast to the. Four referential lexical bundles were selected, which are with regard to the, in the course of, a wide range of and the degree to which. Finally, four bundles belonging to the participant-oriented type were selected, which are it should be noted, play an important role, take into account that, and it is possible that.

\section{Preparation of Concordance Print-outs}

The inductive corpus-based method of teaching relied on printed out concordances of fifteen targeted lexical bundles taken from The Corpus of Contemporary American English (COCA), URLhttps://corpus.byu.edu/coca/. The COCA was selected due to its availability as one of the largest and most general electronic corpus of American English that addresses different needs of various disciplines; in other words, it includes contextualized language taken from divergent fields providing various options for selection of the targeted lexical bundles with regard to the participants' proficiency level, age, and culture. Accordingly, some topics were removed, mostly from political, medical and judicial fields, either because their content was not familiar to the participants' knowledge and age, or because the language used was too difficult with regard to the proficiency level of the students. There were also some concepts included in the components that were unacceptable in participants' culture (see Appendix A for a sample of print-out concordance).

\section{Procedure}

As previously mentioned the study was conducted as part of an 
English course, which mainly involved training the students on using the four skills of the language (reading, listening, speaking, and writing) relevant to their level. With regard to the previous course content before the study, it did not include teaching sophisticated single or grouped words, as it was not one of the course's objectives. This was also checked in the participants' former written work delivered in their previous course, which did not include any of the targeted lexical bundles.

The application of corpus-based instruction followed some steps. Firstly, the teacher started by distributing printed out concordances of the targeted lexical bundles among the students, and then asked them to read the examples in the sheets (see Appendix A). While the students were reading, the teacher would ask them to focus on the bolded phrases (one lexical bundle included in all the examples). The next step they were asked to try to infer the meaning of the targeted lexical bundle with reference to the various examples they were reading. After holding a discussion with the participants on the meaning and agreeing on it, the teacher would ask students to work in groups and look again at the examples and infer their function drawing their attention to what preceded or followed the bundle in each sentence.

After that, the teacher would ask students to give their own examples on each of the lexical bundles planned for each session (either 2 or 3 lexical bundles as some sessions included tests on the other material of the course leaving less time for teaching the targeted lexical bundles) and then give them direct feedback. At the end of the session and after having class discussions on the targeted lexical bundles, the students would take a printed out concordance of a new lexical bundle as homework, from which they were asked to elicit the meaning, use and function of the new lexical bundle same way as they had learnt to do it in class.

\section{A Whole Group Interview}

After the YLE course had finished, the researcher had recorded a 
semi-structured whole group interview (see Appendix B) with the participants to allow them to reflect on the new learning experience. The reason for holding a whole group interview was because it was a new experience for all the participants, who were of the same young age and similar education background, therefore, they could be more encouraged to reflect freely on their views while listening to others, who have been through the same experience. The data collected from the interview was examined and analyzed by the researcher to answer the research question.

\section{Data Analysis}

The verbal data collected from the interview (see Appendix C) was qualitatively analyzed by writing down the main ideas relevant to each interview question. This is followed by using Braun and Clarke's (2006) thematic analysis approach, which relied on the identification and interpretation of selective themes (or patterns). Three themes were sought in the analysis of the participants' interviews, which were the effectiveness of corpus-based instruction in the acquisition of lexical bundles, the problems the participants encountered during the learning process, and their recommendations for a more successful learning experience.

\section{Results}

The first theme of analysis presents the participants' attitudes towards the effectiveness of corpus-based teaching, which relied on printed out concordances as one basic tool of this method. Six learners of this group, the other member did not make comments on this part, appreciated corpus instruction and described it as a new successful teaching method that they had never experienced in their institution before. They also confirmed the fact that the new method of teaching enabled them to use more lexical bundles (they used the term linking words when they wanted to refer to lexical bundles) in their school writing assignments, which they did after they had finished the ten week English course. They stressed the idea that they could use the acquired 
lexical bundles in any writing genre, specifically essays and research.

The printed out concordances and their positive influence on the acquisition of the targeted lexical bundles were appreciated by the participants. They stressed the vitality of the concordances due to the big amount of examples they offered. They added that the difficulty of some examples included in the print-outs was managed via reading more various examples given in the same print-outs, until eventually they could comprehend the meaning, and the function of each targeted lexical bundle.

Six participants mentioned that they had a good learning experience, which resulted in the fluent production of each lexical bundle. They explained that the difficulty of the words within a bundle did not make a difference, probably since they dealt with each lexical bundle as one entity.

One of the participants explained that she was enabled to produce correct language since she used the acquired lexical bundles correctly in meaning and structure, the other six participants agreed with her. Another participant elucidated that his writings had become more distinctive due to the production of new phrases that linked between the ideas of the writing (the phrase "relationships between sentences" was used instead of the word "linking" sometimes), which was also confirmed by the other six participants. It was noticed that there were some lexical bundles that were used more than the others. One of them selected play an important role, and another one selected on the other hand and take into account that. Stressing the importance of correctly using the targeted lexical bundles in meaning and structure shows the effectiveness of instruction in the acquisition of the targeted lexical bundles on one hand, and the participants' awareness of a successful acquisition process, on the other hand.

One of the problems that the participants agreed upon in the interview was the difficulty of some topics in the concordance lines. This 


\section{Dina M. Nour}

problem could have hindered the acquisition process sometimes, specifically that some topics were unfamiliar to them. According them, this problem was dealt with via the teachers' help sometimes, or by using the internet to search for meanings of the complicated topics (this was part of the homework activity). The participants added that there was another helpful way that enabled them to understand many of the lexical bundles without any help, which was reading more the examples from the concordance lines. They concluded that learning about the selected lexical bundles was difficult only at the beginning of the course. However, they explained that with more learning and practice, the whole learning operation was more facilitated.

There was another difficulty lying in the composite of some lexical bundles. The participants agreed that "some linking words" were more familiar and easier to understand than the others, one of them mentioned play an important role as an example. The participants also agreed that "some linking words" were more complicated to comprehend, one of them mentioned take into account that as an example. However, they did not totally agree on their selection of easy or difficult lexical bundles.

Although they said they got used to the new method of teaching, they pointed out that the time given to such a new experience was not enough. This included the time of the course as a whole (ten weeks) or the time devoted for teaching the selected lexical bundles in each session (about half an hour).

After discussing the main problems they had encountered, the participants had their suggestions about the improvement of the learning experience. In light of this, they all requested more activities and worksheets on lexical bundles so that they could do more practice on them, stressing the importance of being provided with continuous direct feedback on their use of lexical bundles. One participant suggested having more visual instructional techniques (like electronic means) to provide them with more examples on the selected lexical bundles. 
Another one recommended the provision of various informative links where they could investigate more on the targeted lexical bundles, specifically in assignments. Although five of the participants believed that 15 lexical bundles were enough for the duration of a ten-week course, one participant emphasized that learning 20 lexical bundles per course would be a better option due to the importance of such word groupings.

\section{Discussion}

The analysis of interviews showed a positive attitude of the participants towards the corpus method of teaching and the acquisition of lexical bundles. This was verified in the participants' positive responses towards the various contextualized examples included in the printed out concordances. In spite of the identification of some drawbacks of this method such as the difficulty of the concordance lines sometimes, the participants agreed that it was a total new productive experience. This same positive attitude towards corpus-based instruction was also reported by Chatpunnarangsee (2013) about the participants of her study.

The most effective tool of this teaching method from the participants' perspective was the numerous examples presented on each lexical bundle. According to the participants, this sum of examples enabled them to recognize the meaning and form of each lexical bundle, which they needed in order to produce it correctly specifically in their formal writing (essays and research papers) even after they had finished the English course. In their perception, the more the examples they had, the more they could learn about the meaning and form of lexical bundles in order to correctly use them in their writing tasks. This implies the vitality of exposing students to an adequate amount of examples for each targeted lexical bundle in order to use it appropriately in their linguistic product, and it also implies the learners' awareness of a successful acquisition process. The efficiency of exposing learners to numerous contextualized examples of lexical bundles, specifically during writing 


\section{Dina M. Nour}

sessions applying corpus-based instruction, was also concluded by Cortes (2007), and Appel (2011).

The tendency of doing more practice on the new lexical bundles at home was appreciated by the participants, which highlights the importance of implementing homework tasks in teaching material. This positive attitude towards having homework on the new language was in one of the recommendations about employing electronic means for the study of lexical bundles. This contradicts Chatpunnarangsee (2013) result, since the participants in her study showed negative attitude towards having extra assignments due to their busy academic schedule on one hand, and due to the difficulty of the concordance data, which was a new experience for them, on the other hand. One possible explanation for this contradiction could be due to the demographic differences between the participants of both studies.

The participants reacted negatively to the lack of various activities on the targeted lexical bundles. They agreed that the provision of activities was needed for a more productive learning process. Then the necessity of being assigned homework on the targeted lexical bundles was meant to prolong the training period, which was not enough during the sessions. With regard to the different recommendations they made about the activities that could be integrated in the course, it was noticeable that the activities recommended by the participants were more relevant to school students; and they mostly addressed the visual learning skills.

The importance of the integration of different activities was also highlighted by Hyland and Tse (2009), Kazemia, Katiraeib, and Rasekhe (2014), and Ranjbar, Pazhakh, and Gorjian (2012) due to their significance in the acquisition of lexical bundles. Li and Schmitt (2009) also concluded that the utilization of any kind of activities on multi-word units would result in a facilitated learning process of the targeted lexical bundles. It was also pointed out by Ucar (2017) that using activities of 
different types would not only improve the acquisition process of formulaic sequences, but it would also help learners retain the acquired language.

The participants reported that they had encountered problems with the new method of teaching only at the beginning of the course, specifically with the difficulty of grasping some unfamiliar topics in the concordance lines. After getting familiar with the new way of instruction, they faced other problems such as the lack of practicing time. All the participants considered the inadequacy of the time needed for practicing the new language as a major problem. This could be one of the reasons why the participants appreciated the idea of having homework and extra activities in order to extend the practicing time of the new language. This same idea of providing extra time for practicing the lexical bundles targeted for corpus-based instruction was also pinpointed by Chatpunnarangsee (2013).

The inadequacy of practice time of the new lexical bundles was considered as a substantial problem by the participants, who needed more time to comprehend and process all the new lexical bundles in order to acquire them and use them correctly in their linguistic product. This was implied in the participants' inability to recall all the targeted lexical bundles during the interview. The negative impact of the lack of practice time on the acquisition process of lexical bundles in the way it could obscure their production resonates with the findings of Chatpunnarangee (2013), and Cortes (2007).

The necessity of an extended practice time to maintain the acquisition of the targeted lexical bundles was also pinpointed by AlHassan and Wood (2015), and El-Dakhs, Prue, and Ijaz (2017). According to them, a prolonged practicing time did not only help participants acquire and internalize the new multi-word units, but it also led to the comprehension of their structures and usage, and enabled learners to correctly implement them in writing. 


\section{Dina M. Nour}

Accordingly, an extended time is needed to constantly expose learners to the targeted lexical bundles, with the aim of enriching the learners' linguistic knowledge of the new languague, so that that they would acquire the targeted lexical bundles and produce them abundantly. This resonates with Al-Hassan and Wood's (2015) finding, which revealed that the intensive instruction of lexical bundles resulted in the wide use of various types of lexical bundles in the written production of the learners.

The number of the words combined in each lexical bundle, or the difficulty of the selected lexical bundle as a whole was not stressed by the participants. According to them, the learning process was facilitated by the number of examples they read on each lexical bundle, and the teacher's guidance. Although corpus- based instruction is one type of DDL, which is basically about autonomous learning, some factors like the early age of the participants and their lack of autonomous learning experience, forced the teacher sometimes to interfere in order to follow up the learners' progress during the new learning process.

According to the participants, the teacher played a significant role in guiding them during the application of corpus-based instruction, and by drawing different discussions around the new language. The application of corpus-based instruction might confine the teacher's role to monitoring the participants while sifting through the concordance lines. This was the case in the present study to a great extent; however, the teacher had to interfere sometimes if there was any sort of confusion about a targeted lexical bundle. To elucidate, the teacher's interference took place only as a final resort if she sensed that the participants had failed completely to elicit either the meaning or the form of some complicated lexical bundles. When the teacher had to interfere sometimes, she took into account the participants' proficiency level and age, and the fact that it was a novice learning experience for school students, who needed her guidance at least at the beginning of the study. 
The vitality of the teacher's guidance even with the application of DDL methods, such as the utilization of corpus-based instruction, was pinpointed by Chatpunnarangsee (2013), who revealed that the lack of the teacher's interference might have been one of the reasons why the participants could not produce more correct lexical bundles in their writing.

\section{Conclusion}

According to the participants' views in this study, it has been found that corpus-based instruction has been proved effective in the acquisition of the targeted lexical bundles. There are some distinctive instructional features that have been pinpointed by the participants such as the implementation of abundant contextualized examples of the targeted lexical bundles, and variety of activities; along with the provision of an extensive practice time. The teacher's role has also been proved vital, specifically for school students, who are not totally familiar with autonomous learning and could benefit more from direct teaching.

\section{Pedagogical Implications}

There are some pedagogical implications relevant to the main aim of the study. The provision of numerous contextualized examples, which are linguistically appropriate for the learners' proficiency level, is recommended for a fruitful learning experience. The repeated exposure of learners to these examples is one fundamental step for the acquisition of the targeted lexical bundles, along with designing plenty of activities that address learners' different ages and learning skills.

In order to ensure the integration of the new lexical bundles into the learners' linguistic knowledge, it is better to select a reasonable number of lexical bundles, depending on the learners' proficiency level, to be taught in an extended period of time. This has been proved more productive than teaching an extensive number of lexical bundles without providing the learners enough practice time, which could hinder the 


\section{Dina M. Nour}

acquisition process, specifically that some lexical bundles are more complicated than the others and need more practice.

The employment of electronic means in instruction, which is favored by learners of this technological era, plays a vital role in facilitating the teaching and the learning process. Giving homework on the new language has been also proved vital to sustain the acquisition of the targeted lexical bundles, whether it aims at seeking an explanation for a new lexical bundle or doing a task involving its use.

Finally, since the teacher's role is basic, especially for school students, the teachers assigned to teach lexical bundles using corpusbased instruction should be knowledgeable about the linguistic feature they are implementing in the courses they are teaching, and the teaching process adopted. Add to this, they need to be well-qualified and trained, specifically for corpus-based instruction. It is also the responsibility of teachers to select the type and number of lexical bundles relevant to every course they teach, in light of the knowledge they have about the participants.

\section{Limitations of the study}

There are some limitations to be taken into consideration in this study. The first limitation is the noticeable small size of the sample, which could be a problem when seeking plenty of various attitudes regarding the main topic of the study. The second limitation is related to the availability of an adequate time for the study. The problem lied in the short time of the course (ten weeks), and the short time devoted for teaching the targeted lexical bundles in every session (30 minutes). Consequently, the learners were not exposed enough to the new language, and they did not have enough practice on the new lexical bundles.

There is another limitation regarding the targeted lexical bundles, as they could be construed as difficult for the participants' proficiency level since they could not recall all of them during the interview. 
However, the functional targeted lexical bundles used in this study were considerably selected with regard to the learner's intermediate level, so if the acquisition did not take place, it could be ascribed more to the shortage of learning and practicing time.

\section{Recommendations for further research}

It is recommended to investigate the types of lexical bundles that should be implemented in different linguistic courses. This is in addition to investigating the appropriate method of teaching that is relevant to each selected type of lexical bundles, including the design of specific courses and developing materials for this purpose.

With regard to the instruction of lexical bundles, especially the application of explicit methods such as corpus-based instruction, it is recommended to investigate the most effective tools of teaching of lexical bundles in previous research and merge them in one mixed method of teaching, taking into consideration the ages and proficiency levels of the learners when preparing the materials. It is also suggested to investigate the difference between electronic and non-electronic settings during the application of corpus-based instruction. Developing course materials and text books specifically designed for teaching lexical bundles, where a variety of activities addressing different learning skills are integrated in the course, is also recommended for research. 


\section{Dina M. Nour}

\section{Bibliographie}

Adel, A., \&Erman, B. (2011). Recurrent word combinations in academic writing by native and non-native speakers of English: A lexical bundles approach. English for Specific Purposes, 31, 81-92. Doi:10.1016/j.esp.2011.08.004

Al-Hassan, L., \& Wood, D. (2015). The effectiveness of focused instruction of formulaic sequences in augmenting L2 learners' academic writing skills: A quantitative research study. Journal of English for Academic Purposes, 17, 51-62. Retrieved from http://dx.doi.org/10.1016/j.jeap.2015.02.001

Allan, R. (2016). Lexical bundles in graded readers: To what extent does language restriction affect lexical patterning? System, 59, 61-72. Retrieved fromhttp://dx.doi.org/10.1016/j.system.2016.04.005

Amirian, Z., Ketabi, S., \&Eshaghi, H. (2013). The use of lexical bundles in native and non-native post-graduate writing: The case of applied linguistics MA theses. Journal of English Language Teaching and Learning, 11, 1-29. Retrieved fromhttps://www.researchgate.net/publication/278329958_The_Use _of_Lexical_Bundles_in_Native_and_Nonnative_Postgraduate_Writing_The_Case_of_Applied_Linguistics_ MA_Theses

Appel, R. (2011). Lexical bundles in university EAP exam writing samples: CAEL test essays (master's thesis). Retrieved fromhttps://curve.carleton.ca/system/files/etd/7b696a05-9e7e-4450af47-

c00c37a1f8a6/etd_pdf/1484e943a6159c1f6e309bb3069d98fa/appel lexicalbundlesinuniversityeapexamwritingsamples.pdf. (978-0-49483147-2)

Braun, V., \& Clarke, V. (2006). Using thematic analysis in psychology. Qualitative Research in Psychology, 3(2), 77-101 DOI: 10.1191/1478088706qp063oa 
Chatpunnarangsee, K. (2013). Incorporating corpus technology to facilitate learning of English collocations in a Thai university EFL writing course (Doctoral dissertation, Indiana University). Retrieved from https://search.proquest.com/docview/1377283083 UMI Number: 3562624

Cortes, V. (2007).Teaching lexical bundles in the disciplines: An example from a writing intensive history class. Linguistics and Education, 17, 391-406.Doi: 10.1016/j.linged.2007.02.001

El-Dakhs, D., Prue, T., \& Ijaz, A. (2017). The effect of explicit instruction of formulaic sequences in pre-writing vocabulary activities on foreign language writing. International Journal of Applied Linguistics \& English Literature, 6(4), 2123.Doi:10.7575/aiac.ijalel.v.6n.4p.21

Guan, X. (2013).A study on the application of data-driven learning in vocabulary teaching and learning in China's EFL class. Journal of Language Teaching and Research, 4(1), 105-112.

Doi:10.4304/jltr.4.1.105-112

Hanafiyeh, M., \&Keshi, A. K. (2013).The effect of corpus-based instruction and thesaurus-based teaching on Iranian EFL learners' grammatical knowledge.Journal of Basic and Applied Scientific Research, 3(2), 167-179. Retrieved from http://www.textroad.com/pdf/JBASR/J.\%20Basic.\%20Appl.\%20Sc i.\%20Res.,\%203(2)167-179,\%202013.pdf

Huang, K. (2015). More does not mean better: Frequency and accuracy analysisof lexical bundles in Chinese EFL learners' essay writing. System, 53, 12-23.Doi:.org/10.1016/j.system.2015.06.011

Hyland, K. (2008). Academic clusters: Text patterning in published and postgraduate writing. International Journal of Applied Linguistics, 18(1), 41-62.Doi: 10.1111/j.1473-4192.2008.00178.x

Hyland, K., \& Tse, P. (2009). Academic Lexis and Disciplinary Practice: 


\section{Dina M. Nour}

Corpus Evidence for Specificity.IJES,9(2), 111-129. Retrieved from http://revistas.um.es/ijes/article/view/90781/87581

Jafarpour, A. A., Hashemian, M., \&Alipour, S. (2013).A corpus-based approach toward teaching collocation of synonyms.Theory and Practice in Language Studies, 3(1), 51-60. Doi:

10.4304/tpls.3.1.51-60|?7

Kashiha, H., \&Chan, S. H. (2015).A little bit about: Differences in native and nonnative speakers' use of formulaic Language. Australian Journal of Linguistics, 35(4), 297-310. DOI:

$10.1080 / 07268602.2015 .1067132$

Kayaoğlu, M. N. (2013). The use of corpus for close synonyms. The Journal of Language and Linguistic Studies, 9(1), 128-144. Retrieved from http://www.jlls.org/vol9no1/128-144.pdf

Kazemia, M., Katiraeib, S.,\&Rasekhc, A. E. (2014).The impact of teaching lexical bundles on improving IranianEFLstudents' writing skill. Procedia-Social and Behavioral Sciences, 98, 864 - 869. Retrieved from https://doi.org/10.1016/j.sbspro.2014.03.493

Krummes, C., \& Ensslin, A. (2015). Formulaic language and collocations in German essays: From corpus-driven data to corpus-based materials. The Language Learning Journal, 43(1), 110-127. Retrieved fromhttp://dx.doi.org/10.1080/09571736.2012.694900

Kweon, S.-O.,\& Kim, H.-R. (2008). Beyond raw frequency: Incidental vocabulary acquisition in extensive reading. Reading in a Foreign Language, 20(2), 191-215. Retrieved from http://nflrc.hawaii.edu/rfl/October2008/kweon/kweon.html

Li, J., \& Schmitt, N. (2009). The acquisition of lexical phrases in academic writing: A longitudinal case study. Journal of Second Language Writing, 18, 85-102. Doi:10.1016/j.jslw.2009.02.001

Leńko-Szymańska, A. (2014).The acquisition of formulaic language by EFL learners.International Journal of Corpus Linguistics, 19(2), 
Corpus-based Instruction and the Acquisition of Functional Lexical Bundles: EFL Egyptian School Learners' Perspective

225-251. Doi: 10.1075/ijcl.19.2.04len

Long, M.H. (1997). Focus on form in task-based language teaching.

Retrieved from

https://woucentral.weebly.com/uploads/7/4/6/9/7469707/long_1997 intro_focus_on_form.pdf

Meunier, F. (2012). Formulaic language and language teaching. Annual

Review of Applied Linguistics, 32, 111-129.Doi:

$10.1017 / \mathrm{S} 0267190512000128$

Paquot, M., \& Granger, S. (2012). Formulaic language in learner corpora.

Annual Review of Applied Linguistics, 32, 130-149.Doi:

10.1017/S0267190512000098

Ranjbar, N., Pazhakh, A., \&Gorjian, B. (2012). The effect of lexical bundles on Iranian EFL learners linguistic production fluency. International Education Studies, 5(4). Doi:10.5539/ies.v5n4p243

Ruan, Z. (2017). Lexical bundles in Chinese undergraduate academic writing at an English medium university. RELC, 48(3), 327-340. DOI: $10.1177 / 0033688216631218$

Schmidt, R. W. (1990). The role of consciousness in second language learning. Applied linguistics, 11(2), 129-158. Retrieved from https://nflrc.hawaii.edu/PDFs/SCHMIDT\%20The\%20role\%20of\% 20consciousness \%20in\%20second\%20language\%20learning.pdf

Ucar, S. (2017).A corpus-based study on the use of three-word lexical bundles in the academic writing by native English and Turkish nonnative writers. English Language Teaching, 10(12), 28-36.Doi: 10.5539/elt.v10n12p28

The Corpus of Contemporary American English COCA (2019). https://corpus.byu.edu/coca/. 


\section{Appendix A}

Adapted from https://corpus.byu.edu/coca/

\section{A sample of a print-out concordance}

FIND SAMPLE: $100 \underline{200} \underline{500} \underline{1000}$

PAGE: $<<<1 / 63>>>$

\begin{tabular}{|c|c|c|c|c|c|c|c|}
\hline \multicolumn{3}{|c|}{$\begin{array}{l}\text { Click For More } \\
\text { Context }\end{array}$} & [?] & $A \vee E$ & ELI & & $\begin{array}{ll}\text { Choose List } \\
+ \\
{[?]}\end{array}$ \\
\hline 1 & 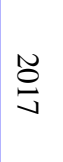 & 瑎 & $\begin{array}{l}\text { Washington } \\
\text { Times }\end{array}$ & A & B & $\mathrm{C}$ & $\begin{array}{l}\text { former head of the DOJ's Civil Rights Division, on } \\
\text { Twitter. \# In addition to the murder charge, } \\
\text { Charlottesville authorities said Mr. Fields has also } \\
\text { been charged with }\end{array}$ \\
\hline 2 & 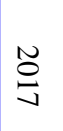 & $\sum_{\text {盂 }}$ & $\begin{array}{l}\text { New York } \\
\text { Times }\end{array}$ & A & B & $\mathrm{C}$ & $\begin{array}{l}\text { biogas plant (the building itself is made from recycled } \\
\text { glass bottles). In addition to the electric boats (similar } \\
\text { to wide, flat pontoon boats), the }\end{array}$ \\
\hline 3 & $\stackrel{\stackrel{N}{O}}{v}$ & 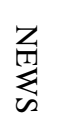 & $\begin{array}{l}\text { Charlotte } \\
\text { Observer }\end{array}$ & A & B & C & $\begin{array}{l}\text { the image, " he said. Posters communicate style, tone } \\
\text { and metaphor in addition to the essentials of band } \\
\text { name, time, date, place and tickets. }\end{array}$ \\
\hline 4 & $\stackrel{N}{\stackrel{O}{\Xi}}$ & 臺 & $\begin{array}{l}\text { Virginian- } \\
\text { Pilot }\end{array}$ & A & B & C & $\begin{array}{l}\text { of Zoos and Aquariums. Four are at the aquarium in } \\
\text { Virginia Beach. In addition to the babies and their } \\
\text { father, there's another male named Sanchez in his }\end{array}$ \\
\hline 5 & $\stackrel{N}{\ominus}$ & 索 & $\begin{array}{l}\text { Minneapolis } \\
\text { Star Tribune }\end{array}$ & A & B & C & $\begin{array}{l}\text { of support already. " \# Some employees said a culture } \\
\text { change is needed in addition to the policy change. \# } \\
\text { " While policy may say that a mother can }\end{array}$ \\
\hline 6 & $\stackrel{N}{\ominus}$ & $\sum_{\text {集 }}$ & $\begin{array}{l}\text { Los Angeles } \\
\text { Times }\end{array}$ & A & B & C & $\begin{array}{l}\text { Felicity Huffman), to investigate what's happening to } \\
\text { the workers. \# In addition to the farm story line, we } \\
\text { meet several other characters in the first half }\end{array}$ \\
\hline 7 & $\stackrel{N}{\ominus}$ & 亘 & $\begin{array}{l}\text { Washington } \\
\text { Times }\end{array}$ & A & B & C & $\begin{array}{l}\text { extra point since } 1997 \text {. \# The field also looks much } \\
\text { different visually. In addition to the walls that } \\
\text { surround the field, there are nets that extend outward } \\
\text { from }\end{array}$ \\
\hline
\end{tabular}




\section{Corpus-based Instruction and the Acquisition of Functional Lexical Bundles: EFL Egyptian School Learners' Perspective}

\section{Appendix B}

\section{Interview Questions}

1. Do you remember these phrases (showing them the concordance lines with bolded lexical bundles)? Have you used any of them, or others that look like them, before the course? If yes, give examples.

2. What do you think about the size of these phrases, did it cause any problems while learning them? (4 words each)

3. Describe how useful these phrases were for your writing tasks.

4. In matter of quantity, what do you think about the 15 phrases you studied throughout the course? In other words, explain why you think they were enough, or too many, or too few.

5. Do you think the time given for learning these phrases was enough? What are your suggestions?

6. Explain if you find these phrases easy or difficult to understand and give reasons.

7. Explain what you like and what you dislike about the way of teaching these words. (showing concordances print outs to treatment group)

8. Could you understand the meaning of these phrases on your own after reading examples on them or only after the teacher had discussed them with you?

9. Do you think teaching these phrases help you learn the way to use them correctly in writing?

10. What do you think you need in order to learn how to use these phrases without problems in writing? In other words, talk about the kind of teaching or material you think will help you more.

11. Generally, do you think these phrases could help in improving your writing?

12. You have already taken 15 of these phrases and there are much more in the language, so in the future, keeping your previous comments in mind, would you want to learn more different phrases like these. Explain your opinion. 


\section{Appendix C}

\section{Main ideas discussed and participants' responses}

\section{Was it their first time or they took something like that before?}

All agreed it is their first time

The size of the phrase

No problem

\section{Were they useful for writing?}

- They said they used in school after the course

- Most of them, about 3, 4,5

- They select the bundle according to the topic of writing not according to the difficulty of the bundle itself.

\section{How did they change their writing?}

- Link sentences in a way that was not given in school before so they get better grades

- Improved certain types of writing like essays and research

- Make our writing different from others by new words to link between two sentences / have relationships between each sentence - even when speaking we apply these words

- One of them selected 'play an important role' as an important bundle that he used most of the time, another one selected 'in relation to', another one selected 'on the other hand', 'take into account that'

\section{The quantity}

- Half of interviewees believed that the number was enough others believed they could have taken more

- Suggestions 17 bundle, most of them said 20, others suggested 10

Time

- They thought that time was enough and they needed more except for a few

\section{Level of difficulty of lexical bundles}

- At first it was difficult to understand, but discussions and examples and activities - and after participation and activities they became easy - also after being given many examples - after studying them they became easy (he meant homework)

- One of them said to overcome difficulty he would search the internet for their meaning

Way of teaching

- The examples (concordance) were really important because they were 
Corpus-based Instruction and the Acquisition of Functional Lexical Bundles: EFL Egyptian School Learners' Perspective

many so if I couldn't understand one I would read others, at least I would understand 3 of them - more than one example made the meaning clear

- Topics included in the examples - some of them were difficult

- They could understand some of the examples on their own (specifically the familiar ones) and others after discussing them with the teacher, but most of them said they could understand them on their own - it depends on the difficulty of the example or the combination of the bundle itself. Two things: the combination can be difficult - the example including it can be difficult.

- In relation to writing, after being taught the bundles were you be able to produce correct writing, they answered and correct meaning also - what about the grammar - they answered it helped (teaching and sheets) they needed both for good writing.

- One of them explained that before the course he could not write good essays

What more do you need (teaching or material) to use these phrases in writing

- More activities

- More worksheets

- More visuals

- More links on Google on these phrases (for assignments)

- More examples (concordances) and answer them

Conclusively, were these phrases of benefit to writing?

They all agreed

What about these phrases (lexical bundles), would you like to learn more of them in the future?

They all agreed

At the beginning they were difficult

They kept repeating that they preferred checking them on the internet

They believe that it would be better to study two per week or three maximum instead of four. 